\title{
Systemic Sarcoidosis Associated with Exposure to Borrelia burgdorferi in a 21-Year-Old Man
}

\author{
Lars van Dee ${ }^{1}$, Mylene Stehouwer ${ }^{2}$, Thomas van Bemmel ${ }^{2}$ \\ ${ }^{1}$ Universitair Medisch Centrum, Utrecht, The Netherlands \\ ${ }^{2}$ Gelre Ziekenhuizen, Apeldoorn, The Netherlands
}

How to cite this article: van Dee L, Stehouwer M, van Bemmel T. Systemic sarcoidosis associated with exposure to Borrelia burgdoferi in a 21-year-old man. EJCRIM 2018;5: doi:10.12890/2018_000942.

Conflicts of Interests: The Authors declare that there are no competing interests.

Acknowledgements: The authors thank A. Stemerding (Medical Microbiology, Gelre Ziekenhuizen, Apeldoorn) for her excellent help with the interpretation of the neuroborreliosis diagnostics.

This article is licensed under a Commons Attribution Non-Commercial 4.0 License

\section{ABSTRACT}

Objective: Here we describe a rare case of systemic sarcoidosis in a healthy young man with neuroborreliosis as a putative trigger.

Case: A 21-year-old forestry worker was diagnosed with systemic sarcoidosis involving his lungs, kidneys and skin. Additional diagnostics revealed signs indicative of a recent infection with Borrelia burgdorferi. The patient was treated successfully with prednisolone and antibiotics. Conclusion: Sarcoidosis is a multisystem granulomatous disorder of unknown aetiology. This case suggests that an infection with B. burgdorferi, the causal agent of Lyme disease, could act as a trigger for sarcoidosis.

\section{LEARNING POINT}

- We should maintain a high index of suspicion for underlying infectious processes like neuroborreliosis in patients with new-onset sarcoidosis before starting immunosuppressive regimens.

\section{KEYWORDS}

Borrelia burgdorferi, neuroborreliosis, sarcoidosis

\section{CASE DESCRIPTION}

A 21-year-old male forestry worker with a history of recent retrobulbar headaches and a droopy left eyelid was seen at the emergency department because of progressive bilateral swelling and redness of his legs. Previous analysis of his headaches by a neurologist showed no abnormalities and the complaints were interpreted as non-specific, cluster-like headaches.

Over the previous 3 weeks, the patient had experienced progressive swelling, redness and skin peeling of both legs. In addition, his symptoms included a stinging pain behind his sternum, fatigue, weight loss, loss of appetite, thirst and nycturia, although the headaches had stopped. Due to his profession, he frequently encountered tick bites. He used no medication, had stopped smoking 2 years earlier and reported no alcohol or drug use.

Examination was unremarkable except for bilateral pitting oedema of the lower legs and diffuse, confluent, flat, red and scaling lesions. The patient further presented with a frequent dry cough. 


\title{
METHODS AND PROCEDURES
}

The combination of symptoms and bilateral hilar adenopathy on chest X-ray (Fig. 1) were indicative of sarcoidosis. Additional laboratory tests, imaging studies and an endoscopic ultrasound (EUS) with lymph node biopsies were performed (Table 1). Most notably, the laboratory results showed an elevated level of creatinine and ionized calcium, in keeping with the systemic effects of sarcoidosis. Other haematological, endocrine, auto-immune and infectious causes (tuberculosis, HIV, lues) were excluded (data not shown). A definite diagnosis of systemic sarcoidosis with involvement of the lungs, skin and kidneys was made when non-caseating granulomas were described in the lymph node and skin biopsies. While waiting for the results, the patient received hyperhydration therapy and infusion with bisphosphonates for his hypercalcaemia, with minimal effect. However, after he started high-dose prednisolone, the hypercalcaemia as well as renal function normalised within only 2 days, further supporting the diagnosis of sarcoidosis.

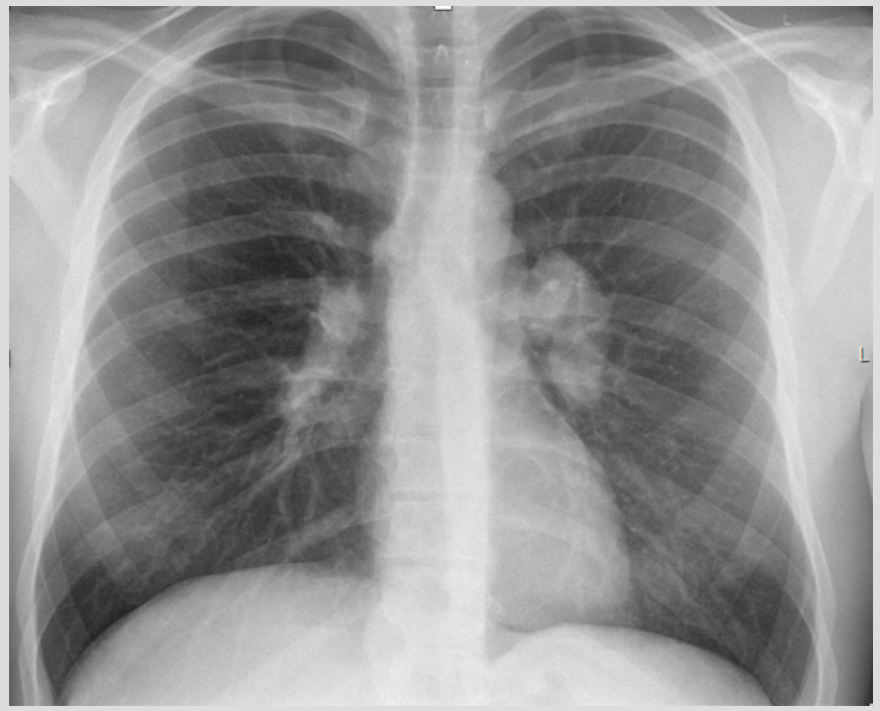

\begin{abstract}
Figure 1. Chest $X$-ray showing clear lung parenchyma, no pleural effusions and normal bone structure. The bilateral hilar lymphadenopathy supports the diagnosis of pulmonary sarcoidosis and was not seen on previous imaging studies
\end{abstract}

\begin{tabular}{|l|l|l|l|}
\hline & Test & Value & Range \\
\hline Laboratory & Creatinine & $153 \mu \mathrm{mol} / \mathrm{l}$ & $60-110$ \\
\hline & Ca2+ & 1.58 & $1.15-1.33$ \\
\hline & Lysozyme & $11.0 \mathrm{mg} / \mathrm{l}$ & $1.2-3.5$ \\
\hline & A.C.E. & $96 \mathrm{U} / \mathrm{l}$ & $<59$ \\
\hline Imaging & Chest X-ray & Bilateral hilar adenopathy \\
\hline & CT & $\begin{array}{l}\text { Symmetric mediastinal and bilateral hilar } \\
\text { adenopathy, ground glass opacities }\end{array}$ \\
\hline Pathology & Endoscopic ultrasound & Lymph node & $\begin{array}{l}\text { Non-caseating } \\
\text { granulomas }\end{array}$ \\
\hline & Biopsy & Skin lesion leg & $\begin{array}{l}\text { Non-caseating } \\
\text { granulomas }\end{array}$ \\
\hline
\end{tabular}

Table 1. Diagnostic findings suggestive of sarcoidosis

The patient's previously unexplained neurological complaints in combination with his job as a forestry worker in an area with a high tick density led to the decision to further pursue diagnostics for Lyme disease. A lumbar puncture was performed 2 days after hospitalization. We found a solitary, immunoblot-confirmed Borrelia burgdorferi IgG response in the serum, and a positive IgG cerebrospinal fluid (CSF)/ serum ratio. Together with signs of inflammation in the CSF, these results are indicative of recent exposure to or infection with $B$. burgdorferi and local antibody production in the CSF (Table 2). 


\begin{tabular}{|l|l|l|l|}
\hline & Test & Value & Range \\
\hline Serum & B. burgdorferi IgM & $31.50 \mathrm{AU} / \mathrm{ml}$ & $<22$ \\
\hline & B. burgdorferi IgM blot & Negative & \\
\hline & B. burgdorferi lgG & 91.01 & $<15$ \\
\hline & B. burgdorferi IgG blot & Positive & \\
\hline Cerebrospinal fluid (CSF) & Total protein & $204 \mathrm{mg} / \mathrm{l}$ & $240-490$ \\
\hline & Glucose & 3.4 & $2.2-3.9$ \\
\hline & Leucocytes & 34 & $<12$ \\
\hline & Erythrocytes & 0 & \\
\hline & $\begin{array}{l}\text { Neuroborrelia IgM } \\
\text { CSF/serum ratio }\end{array}$ & 0.0 (negative) & \\
\hline & $\begin{array}{l}\text { Neuroborrelia IgG } \\
\text { CSF/ratio }\end{array}$ & 2.6 (positive) & \\
\hline & PCR B. burgdorferi & Negative & \\
\hline Skin biopsy & PCR B. burgdorferi & Negative & \\
\hline
\end{tabular}

Table 2. Diagnostic findings suggestive of (recent) infection with Borrelia burgdorferi

The patient was treated with intravenous ceftriaxone for 2 weeks followed by 30 days doxycycline per os in addition to the immunosuppressive therapy for sarcoidosis, with the aim of preventing a flare up of a possible dormant/lingering $B$. burgdorferi infection. The patient recovered quickly within a few days of starting a high-dose prednisolone regime, and was discharged free of symptoms and in good health.

\section{DISCUSSION}

Sarcoidosis is a multisystem granulomatous disorder of unknown aetiology, most commonly affecting young adults who generally present with bilateral hilar lymphadenopathy, pulmonary infiltrations, and skin or eye lesions ${ }^{[1]}$. It has been hypothesised before that an infection with B. burgdorferi, the causal agent of Lyme disease, could act as a trigger for sarcoidosis ${ }^{[2]}$. A Japanese study showed an association with sarcoidosis and B. burgdorferi infection in a region where Lyme borreliosis is endemic ${ }^{[3]}$. In 2000, Danish physicians described the case of a man with neuroborreliosis who developed Löfgren's syndrome and reacted well to treatment with doxycycline ${ }^{[4]}$. In patients with cutaneous sarcoidosis, Borrelia-like organisms have been detected in skin tissue by focus-floating microscopy ${ }^{[5]}$.

This case is a rare presentation of sarcoidosis in a healthy young man with neuroborreliosis as a putative trigger. Unfortunately, the presence of B. burgdorferi DNA could not be confirmed by PCR, as the sensitivity of these tests is notoriously low (around 40\%). In retrospect, the cluster-like headaches reported by the patient a few months before his visit to the emergency department could be explained by a recent episode of neuroborreliosis. This unusual case suggests we should maintain a high index of suspicion for underlying infectious processes like neuroborreliosis in patients with new-onset sarcoidosis before starting immunosuppressive regimens.

\section{REFERENCES}

1. Iannuzzi MC, Rybicki BA, Teirstein AS. Sarcoidosis. N Engl J Med 2007;357:2153-2165

2. Jacob F. Could Borrelia burgdorferi be a causal agent of sarcoidosis? Med Hypotheses 1989;30;241-243

3. Ishihara M, Ohno S, Ono H, et al. Seroprevalence of anti-Borrelia antibodies among patients with confirmed sarcoidosis in a region of Japan where Lyme borreliosis is endemic Graefes Arch Clin Exp Ophthalmol 1998;236;280-284.

4. Derler AM, Eisendle K, Baltaci M, et al. High prevalence of 'Borrelia-like' organisms in skin biopsies of sarcoidosis patients from Western Austria. J Cutan Pathol 2009;36;12621268.

5. Klint H, Siboni AH. Borreliosis associated with Lofgren's syndrome. Ugeskr Laeger 2000;162;4154-4155. 